\title{
Patriotic Fun: Toys and Mobilization in China from the Republican to the Communist Era
}

\author{
Valentina Boretti
}

To celebrate Children's Day in I932, Chinese boys and girls were encouraged to participate in a target-shooting competition. They were to try to pick off Japanese planes, tanks, and warships with bow and arrow, popguns, and balls. In I95 I, the time had come to play "Executing the War Criminals"; with toy rifles or bows, children could take aim at targets with images of Chiang Kai-shek and Harry Truman. ${ }^{\mathrm{I}}$

The use of politicized leisure to mobilize children is pervasive throughout the world, but its expressions in pre-Cultural Revolution China have attracted little attention so far. Focusing on prescribed leisure, this chapter traces a preliminary genealogy of play-training for activism in China and comments on youngsters' reactions. Looking at the deployment of toys to mobilize children from the I9IOs to the early I950s, it investigates the ways in which different regimes employed play and playthings as instruments to foster engagement in struggles of a political, commercial, or military nature.

Although it cannot be assumed that children followed the script closely, a study of how leisure was framed offers insights into notions of nationhood and ideal personhood. It can also provide a perspective on cultural continuities between the Republican and Communist eras, such as constant mobilization and normative opposition to nonpurposeful leisure. Examining the function of toys as instruments of mobilization highlights,

\footnotetext{
' Qian Gengzin, ed., "Ershiyi nian ertong jie huodong baogao (er xu)," Zhejiang minzhong jiaoyu 3 (1932), 47-52; Chen Heqin and Wu Chengqi, "Qiangbi zhanfan,” Xin ertong jiaoyu 6(II) (I95I), 3 I.
} 
moreover, a range of porous boundaries: between toy and tool, fun and seriousness, child and adult, aggression and defense, peace and war.

In both Republican and Communist China, toys were employed to instruct children in what to do and what to be: to make them physically and morally healthy, curious about science, creatively productive, and militant, which did not necessarily signify militarized but rather committed to rallying for the nation. Militancy - or, perhaps more accurately, activism - had more to do with patriotic awareness and preparedness than warlike aggressiveness, although militaristic attitudes might emerge. Against the backdrop of recurring calls for assertive self-defense against actual or perceived besiegement, children were urged to cultivate nonpuerility and participative responsibility. Crucial to this agenda was a discourse of mobilization, formulated by intellectuals, pedagogues, ideologues, and public officials - in short, the experts - and disseminated to urban and rural children, parents, and educators through publications, classroom instruction, and events or campaigns. With its reiteration of tropes and prescriptions that varied only slightly over the decades from one regime to the next, this discourse amounted to a choral enterprise, and it is as such that we shall explore it, rather than focusing on solo voices.

\section{LEISURE AND THE MARTIAL SPIRIT FOR THE REPUBLICAN NEW CITIZENS}

At the turn of the twentieth century, following several defeats and perceived humiliations, the fear was widespread in China that "extinction" to use the evolutionary terminology then in vogue - was near. "Survival" would depend upon renewal. Like their counterparts in other countries, Chinese reformers maintained that national revival ought to start with children. $^{2}$

This putative discovery of children as present and prospective "new" citizens located them in opposition to a (mostly imagined) tradition, construed as oblivious to the peculiarities of childhood and condemned as unable to produce "useful" citizens. Although some, like artist Feng Zikai or writer Lu Xun, did plead for the need to appreciate youngsters as

${ }^{2}$ Carl Ipsen, Italy in the Age of Pinocchio: Children and Danger in the Liberal Era (New York, 2006); Mark A. Jones, Children as Treasures: Childhood and the Middle Class in Early Twentieth Century Japan (Cambridge, MA, 2010). On China, see Andrew F. Jones, "The Child as History in Republican China: A Discourse on Development," positions Io(3) (2002), 695-727. 
such, the dominant discourse, especially from the late I920s onward, remained focused on the value of children to national rejuvenation. New children had to be self-reliant, robust, industrious, well educated, and aware of their responsibility to the nation: Youthfulness was no excuse for eschewing duty. ${ }^{3}$ Because properly nurturing these crucial assets was vital, no aspect of children's lives escaped the interference of experts, who tended to accuse parents of incompetence.

Leisure became a serious matter. Play and toys were discursively recast as tools for nation- and citizen-building because of their capacity to unconsciously train and mold young citizens from infancy. Determination, courage, patriotism, creativity, and cooperativeness could all be fostered through play, if it were properly guided and if suitable toys were used. ${ }^{4}$ In line with the claim that only now were children's inclinations appreciated, playthings were proclaimed a necessity and declared to be extremely influential. "Appropriate" toys, capable of producing the new child, should be not merely entertaining. Chinese experts, like their counterparts elsewhere, did not approve of amusement that served no discernible purpose. ${ }^{5}$ Rather, playthings had to be educational and to help cultivate body and spirit, fostering qualities like love for science, manual inventiveness, and a martial spirit. ${ }^{6}$

Indeed, particular importance was attached to martial spirit. In I935, the Shanghai News Child's Companion informed young readers that the unflattering "sick man of East Asia" sobriquet attributed to China was

${ }^{3}$ Liang Qichao, "Lun youxue” ( 1897 ), in Wu Song, et al., eds., Yinbingshi wenji dianjiao (Kunming, 200I), vol. I, 47-57; Lu Xun, "What Is Required of Us as Fathers Today" (1919), in Lu Xun, Selected Works (Beijing, I980), vol. II, 56-7 I; Xian Baiyan, "Ertong de shehuihua," Funü zazhi 8(2) (I922), 23-27; Song Jie, "Ertong jiuji wenti," Dongfang zazhi 22(I7) (I925), 50-69; Feng Zikai, "Ertong de darenhua," Jiaoyu zazhi I9(7 and 8) (1927), I-3; Pan Shu, “Zenyang zuo yige yingfu guonan de ertong,” Xiao xuesheng 5(5) (I935), I-6; Zhang Yucai, “Xiandai jiating yu ertong jiaoyang," Dongfang zazhi 32(II) (I935), 9I-97.

4 Shen Buzhou, "Lun youyi," Jiaoyu zazhi 4(I2) (I9I2), 21 5-27; Xi Zhen, "Rensheng zhi genben jiaoyu," Funü zazhi 3(8) (I9I7), 4-Io; Chen Heqin, "Ertong xinli ji jiaoyu ertong zhi fangfa," Xin jiaoyu 3(2) (1920), I40-46; Chen Yongsheng, Wan yu chi (Shanghai, I93I).

5 Gary Cross, Kids' Stuff: Toys and the Changing World of American Childhood (Cambridge, MA, I997), ch. 5; Catriona Kelly, Children's World: Growing Up in Russia I890-I99I (New Haven, 2007), I 25-26.

${ }^{6}$ Xu Fuyan, "Wanju yu youzhi jiaoyu zhi guanxi," Funü shibao 9 (I9I3), 24-27; Wei Shouyong, "Ertong wanju wenti," Funü zazhi 3(8) (I9I7), 4-6; Wang Muqing, "Ertong wanju de yanjiu," Zhonghua jiaoyu jie I6(7) (1927), I-3; Chen Jiyun, Wanju yu jiaoyu (Shanghai, I933); Qing Shan, "Ertong wanju jianghua: wanju shi yizhong zhongyao de jiaoyu gongju," Xiandai fumu I(8) (I933), 28-29. 
due to the weakness of its people, which had been caused by the respect traditionally enjoyed by literati to the detriment of military men. This had induced disdain for physical exercise, but the "weak" were to be "eliminated." A martial spirit was, therefore, indispensable if China was to "survive" and end its "humiliation."

This discourse of martial spirit and physical robustness had originated well before the establishment of the Republic in I9I 2. It dated back to the late nineteenth century, when intellectuals - Liang Qichao being the most influential - had declared the Chinese and China to be unfit. Overlooking the importance of martial culture in the Qing empire as well as the fact that Chinese models of masculinity encompassed both literary ability and martial prowess, ${ }^{8}$ reformers maintained that the prominence accorded to the former had begotten physical and spiritual weaklings. Liang advocated respect for martial qualities, which, he claimed, China had possessed in antiquity and ought to recover in order to avoid perishing. ${ }^{9}$ This discourse echoed a much earlier tradition of blaming defeat on flawed masculinity. ${ }^{\text {Io }}$ It also possibly contained a measure of self-orientalization, that is, the reproduction of Euro-American constructs of "the Oriental" as effeminate and incompetent. ${ }^{\text {II }}$ Although healthier empires like Britain also experienced apprehension over masculinity at this time, Chinese anxieties reflected a substantial national crisis. ${ }^{\mathrm{I2}}$ Allegedly inept men and "crippled" women unable to raise vigorous offspring ${ }^{\mathrm{I} 3}$ had to be

7 Guo Pinjuan, "Shangwu jingshen," in Shenbao ertong zhoukan she, ed., Shenbao ertong zhi you (Shanghai, I935), vol. I, I 5-I6.

8 Joanna Waley-Cohen, "Militarization of Culture in Eighteenth-Century China," in Nicola Di Cosmo, ed., Military Culture in Imperial China (Cambridge, MA, 2009), 278-95; Kam Louie, Theorising Chinese Masculinity: Society and Gender in China (Cambridge, 2002).

9 Liang Qichao, "Lun shangwu" (I903), in Yinbingshi wenji dianjiao, vol. I, 6I 5-2I; James R. Pusey, China and Charles Darwin (Cambridge, MA, I983), 260-73; Colin Green, "Turning Bad Iron into Polished Steel: Whampoa and the Rehabilitation of the Chinese Soldier," in James Flath and Norman Smith, eds., Beyond Suffering: Recounting War in Modern China (Vancouver, 20I I), I 56-57.

so Martin W. Huang, Negotiating Masculinities in Late Imperial China (Honolulu, 2006), ch. 4 .

I Song Geng, The Fragile Scholar: Power and Masculinity in Chinese Culture (Hong Kong, 2004), 9.

I2 Stephanie Olsen, Juvenile Nation: Youth, Emotions and the Making of the Modern British Citizen, I880-I9I4 (London, 20I4).

I3 Liang Qichao, “On Women's Education” (I 897), in Lydia H. Liu, Rebecca E. Karl, and Dorothy Ko, eds., The Birth of Chinese Feminism: Essential Texts in Transnational Theory (New York, 2013), I89-203. 
replaced by robust new citizens, ${ }^{14}$ who were to cultivate a martial spirit or outlook. ${ }^{\mathrm{I} 5}$

Fostering a martial spirit in children was meant to induce not militarism but rather physico-spiritual strength, unity, and the ability to mobilize in order to defend and reshape China, culturally, politically, militarily, and commercially. Beginning in the early Republican years, military toys were employed to help nurture a martial spirit so as to create citizens poised to fit into the modern world while infused with the spirit of a heroic past. In the I9IOs and early I920s, pedagogues praised swords and spears as testimonies to ancient soldierly virtues and commended toy soldiers, warships, and firearms as educational because they cultivated imagination, knowledge, awareness of the military, and a martial spirit. ${ }^{16}$ Even foreign toys, like the American-made Daisy Air Rifle, were advertised in 1920 as tools to cultivate boys' "indispensable" martial spirit and to turn China into a strong nation. ${ }^{17}$

The appreciation of military playthings was not universal in China before the late I920s, however, probably because of the association of military iconography with ravaging warlord armies. ${ }^{18}$ Indeed, journalists expressed misgivings about promoting toy soldiers in educational exhibitions, and the widely read Ladies' Journal warned mothers that military toys could give a misleading impression of war as "fun" and also encourage destructiveness. ${ }^{19}$ Children themselves showed mixed reactions. Some boys and girls did apparently enjoy playing with air pistols, arranging toy soldiers against fantasy enemies, and engaging in play battles with friends, ${ }^{20}$ but surveys also revealed that some children ignored or

${ }^{14}$ Andrew D. Morris, Marrow of the Nation: A History of Sport and Physical Culture in Republican China (Berkeley, 2004).

${ }^{5}$ Paul J. Bailey, Gender and Education in China: Gender Discourses and Women's Schooling in the Early Twentieth Century (Abingdon, 2007), 98; Nicolas Schillinger, The Body and Military Masculinity in Late Qing and Early Republican China (Lanham, MD, 20I6), ch. 6.

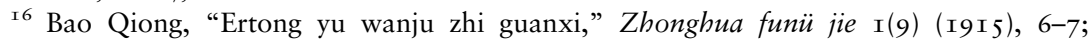
Jia Fengzhen, "Jiaoyu shang zhi wanju guan," Jiaoyu zazhi II(5) (I919), 33, 36, and I I(6) (I9I9), 45; Jiaoyu bu putong jiaoyu si, ed., Ertong wanju shencha baogao (Beijing, I922), I 8, 34, and list of toys: 3, 7, I 8, 60-6I; "Ertong wanju shencha baogao biao," Xin jiaoyu $7(5)$ (I923), 447-48, 452, 46I.

${ }^{17}$ Dongfang zazhi I7I(8) (1920), n.p.

${ }^{18}$ Arthur Waldron, "The Warlord: Twentieth-Century Chinese Understandings of Violence, Militarism, and Imperialism,” American Historical Review 96 (I99I), I073-I IOO.

19 "Kaimu hou Xinwenbao zhi jizai," Xin jiaoyu 9(5) (1924), 961; Jing Xun, "Ertong de youxi ji wanju," Funü zazhi 9(4) (1923), I 23.

${ }^{20}$ Hua Zheru, "Wo zhi youtong shidai," Shaonian zazhi 8(3) (I918), 9-I I; Chow Chungcheng, The Lotus Pool of Memory (London, 1961), 22; Hsieh Ping-ying, Girl Rebel: 
disliked toy weapons. ${ }^{21}$ Children's magazines sometimes featured covers portraying boys (and, very occasionally, girls) playing with toy weapons, and drawings or photographs of guns sent by boys; sometimes they ran stories that deplored the "cruelty" of airguns or associated them with "homicidal battlegrounds." 22

Attitudes began to change in the late I920s after the Nationalist Party (GMD) gained nominal control of most of China and increasingly promoted militant - even militarized - nationalism. The Japanese seizure of Manchuria in I93 I, followed by outright war in 1937, predictably reinforced the discourse of martial mobilization. With rare exceptions, such as Feng Zikai, ${ }^{23}$ experts spoke approvingly of military toys, which frequently appeared in publications.

Children's periodicals praised cultivated yet martial boys who bravely trained to protect the nation. Previously anti-military authors penned stories that urged boys to "polish rifles and sharpen swords." Student poems sang of fearless resistance and willingness to shed blood for China. ${ }^{24}$ Picture cards showed boys "studying military drills" as they played with their toy armaments on the lounge carpet. ${ }^{25}$ While mentioning the potentially harmful effects of warlike games, texts for educators and parents argued that toy weapons could instill a "valiant" spirit along with initiative and attention. ${ }^{26}$ According to experts, the Chinese lacked resoluteness, which ought to be cultivated from infancy. This may have been why kindergartens, before and after the war, were supposed to be equipped with military toys: Playing with bows and arrows or swords

The Autobiography of Hsieh Pingying (New York, [1940] 1975), I9; N. T. Wang, My Nine Lives (San Jose, 200I), 6; Yang Xianyi, White Tiger: An Autobiography of Yang Xianyi (Hong Kong, 2002), 8.

${ }^{21}$ Su Yishi xiao, "Jiangsu Yishi fuxiao di'er jie ertong wanju zhanlanhui jingguo baogao," Jiaoyu zazhi I4(4) (I922), 6-I 2; Zhang Jiuru, “Jiangsu Jiushi fuxiao ertong wanju ceyan baogao," Jiaoyu zazhi I4(8) (1922), I-2, 9.

${ }^{22}$ See photographs in Ertong shijie 8(I)3 (I923), n.p.; Ertong shijie I8(20) (I926), n.p.; drawing by Chen Zhaoyu, "Qiqiang," Ertong shijie I4(I) (I925), n.p.; and stories by Zhuodai, "Qiqiang yu kouqin," Ertong shijie I2(ro) (1924), 3-I I; Boyou, "Wan,” Xiao pengyou I 57 (I925), 34.

${ }^{23}$ Feng Chenbao and Feng Yiyin, eds., Feng Zikai manhua quanji: ertong xiang juan (Beijing, I999), vol. II, I72.

${ }^{24}$ Yu Cheng, "Aiguo nan'er," Ertong shijie 22(3) (I928), 2; Boyou, "Wuzhuang qilai," Xiao pengyou 553 (I933), 26; Zhang Ruxiu, "Zhonghua nan'er,” Xiao xuesheng 7(3) (I937), 42-43.

${ }^{25}$ Erge huapian (Shanghai, I930s), vol. I, series 4, n.p.

${ }^{26}$ Chen Jiyun, Wanju yu jiaoyu, 72; Yu Jifan, Wanju yu jiaoyu (Shanghai, I933), 29, 50 ; Wang Guoyuan, comp., Wanju jiaoyu (Shanghai, I933), 6, 24. 
would "cultivate a martial spirit," and riding hobby-horses would promote bravery in boys. ${ }^{27}$ Revising his earlier views, the influential pedagogue Chen Heqin affirmed that a good toy "must arouse children's martial spirit," and he approved of toy guns, cannons, and warships for fostering courageous and soldierly attitudes. ${ }^{28}$

The discourse on martial spirit centered on "children" and on boys specifically when toy weapons were involved. Its iconography featured boys predominantly. Girls were occasionally mentioned in connection with war toys and games, however, and they did engage in military play. Like the image of the ideal child, mobilization was coded as masculine but was nonetheless intended for both genders. ${ }^{29}$ Military toys may not have been specifically recommended for girls, but the brave-cum-patriotic-cum -scientific attitude that informed the narrative of mobilization and martial spirit was. And so was anti-imperialist activism.

\section{TOYS AND ANTI-IMPERIALIST MOBILIZATION}

If toy-centered mobilization had focused mainly on the inner cultivation of courage and martial spirit before the early i930s, it came to encompass external fronts as well - both commercial and military - during the I930s and early I940s. As the periodical Children's World instructed its young readers in 1933 , national goods and national defense were the means to repel "the imperialists" who intended to "carve up" China. ${ }^{30}$ Girls and boys were thus asked to protect China and their own Chinese-ness by mobilizing against two foreign armies: the toy army of imported playthings and the real army of Japanese invaders.

In China, as elsewhere, ${ }^{3 \mathrm{I}}$ foreign playthings had in fact long been seen as symbols and spearheads of economic and, above all, cultural encroachment. To cite but a few examples, already in I9I 2 the Industrial Magazine of China was arguing that imported toy soldiers

${ }^{27}$ Chen Heqin, "Youzhiyuan zhi shebei," Jiaoyu zazhi I9(2) (I927), 7-8; Su Wanfu, ed., Youzhiyuan de shebei (Shanghai, I935), I9, 99, I3 I-32; Zou Dehui, comp., Youzhiyuan de youxi (Shanghai, I937), I I-I2; Wan Qiyu, Zenyang banli youzhi jiaoyu (Shanghai, I947), 7 .

${ }^{28}$ Chen Heqin, "Wanju” (I925) and "Ertong wanju yu jiaoyu" (1939), in Wanju yu jiaoyu (Kunming, I99I), 36-37 and 108-09.

29 As seen, for instance, in the Girl Scouts: Margaret Mih Tillman, "Engendering Children of the Resistance: Models for Gender and Scouting in China, I9I9-I937," CrossCurrents: East Asian History and Culture Review (e-journal) I3 (20I4), I34-73.

${ }^{30}$ Lianghuan, "Guofang moxing zhizuo fa," Ertong shijie 30(I) (I933), 22-23.

${ }^{31}$ Michel Manson, Jouets de toujours: de l'Antiquité à la Révolution (Paris, 200I), 323-24. 
sporting the flags of both the country of manufacture and China laudably cultivated a martial spirit but at the same time caused harm because they might encourage love for two flags or two countries. In I926, the prominent pedagogue Zhang Zonglin deplored the predominance of foreign toys in kindergartens, expressing concern about their potential impact on the Chinese-ness of children. ${ }^{32}$ Although experts reviled Chinese toys old and new, they repeatedly - but unsuccessfully - urged consumers to buy patriotically.

The crusade for national toys reached a climax after the invasion of Manchuria as Japanese toys became the main target of hostility. Children were reminded not only that opposing "enemy goods" was among their social duties ${ }^{33}$ but also that they must not fund foreigners, as the Japanese were using the profits they earned from exporting toys to annihilate the Chinese. Children penned stories in which boys, patriotically instructed by their teachers, supervised their younger brothers' acquisitions, while girls rectified their mothers' negligent purchases by resolutely exposing dishonest toy sellers. Youngsters were also encouraged to urge their parents to carefully check where toys were made before making a purchase. ${ }^{34}$ Vigilant (adultified) children were thus to police (infantilized) adults, including their own parents. Mobilization also involved manual work: Youngsters were urged to realize that toys could "sell the nation," to stop depending on foreign ingenuity (for Japanese imports were, in fact, still considerable), and instead to use their brains and hands to invent new toys for themselves and for China. ${ }^{35}$

Children unable to make their own toys could purchase playthings manufactured locally. Indeed, patriotism was used in advertising Chinesemade toys. Tanks could "arouse national consciousness." Tank-shaped candy purportedly capable of "cultivat[ing] children to be militant

${ }^{22}$ Li Wenquan, "Shuo wanju," Zhongguo shiye zazhi 5 (I9I2), I 5-16; Zhang Zonglin, "Diaocha Jiang Zhe youzhi jiaoyu hou de ganxiang," Zhonghua jiaoyu jie I 5(I2) (I926), 2; Xu Yasheng, "Ertong wanju de yanjiu," Funü zazhi I5(5) (1929), I6; Susan R. Fernsebner, "A People's Playthings: Toys, Childhood, and Chinese Identity, I909-1933," Postcolonial Studies 6(3) (2003), 282-85.

33 Zhu Yanfu, Ertong jie (Shanghai, I936), 22.

34 Zhou Hui, "Yang wawa," Ertong shijie 30(I I) (1933), 96-98; Wei Suzhen, "Gege he didi mai wanju," Xiao pengyou 595 (I934), 42-43; Jinxi, "Wanju jinkou he zizhi wanju," in Shenbao ertong zhoukan she, ed., Shenbao ertong zhi you, vol. I, 5 I.

35 Dujuan, "Ertong he wanju"; Naichang, "Wanju keyi mai guo," in Shenbao ertong zhoukan she, ed., Shenbao ertong zhi you, vol. I, 39, 53. 
citizens" prompted one boy to proclaim that he would use it to fight the enemy. ${ }^{36}$

Opposing a real foreign army became imperative in the I930s and I940s, and, as in Europe, toys were used to familiarize children with war. ${ }^{37}$ New patterns for time-honoured tangram puzzles reproduced "modern weapons of war" like tanks and anti-aircraft guns. Kindergarten children, it was suggested, could use building blocks to make warships and armoured vehicles, and anti-Japanese "patriotic games" were designed for elementary schools. ${ }^{38}$ The magazine Modern Children offered instructions and drawings for a puzzle featuring the collaborationist politician Wang Jingwei, his wife, and "a Japanese thief": The pieces could be recombined to make "many amusing monster figures," thereby ridiculing the enemy. ${ }^{39}$ Texts offered instruction not only on how to fashion toy animals and figurines, but also on how to make cannons, crafted from thread spools and bamboo, and radish bombs. ${ }^{40}$

Possibly the most significant aspect of this call to miniature arms was the emergence in the mid I93 os of "national defense toys" (a term also used in the United States during World War II $)^{4 \mathrm{I}}$ and, shortly afterward, of "war of resistance toys" ("war of resistance" was the term used for the Second Sino-Japanese War). These new discursive tags turned military playthings into training tools with little ludic significance. Some children did in fact assert that, with the Japanese invasion of Manchuria, the time for recreation was over, which dovetailed with adult invitations to "put toys down" and to focus on trying to support the nation in danger. ${ }^{42}$ Children were apparently to relinquish play and move on to reproducing

${ }^{36}$ China Can advertisement in Yong'an yuekan I (I939), n.p.; Guanshengyuan advertisement in Xiandai fumu I(I) (I933), n.p.; Lien Ling-ling, "From the Retailing Revolution to the Consumer Revolution: Department Stores in Modern Shanghai," Frontiers of History in China 4(3) (2009), 379.

37 Antonio Gibelli, Il popolo bambino. Infanzia e nazione dalla Grande Guerra a Salò (Turin, 2005).

${ }^{8}$ Yuesheng, "Qiqiao xin tu," Ertong shijie 30(6) (I933), 5 I; Shen Baiying, et al., comp., Youzhiyuan gongzuo yibailiushi zu (Changsha, [1936] I939), 52, 302; Morris, Marrow of the Nation, I33.

39 Yang Wuzai, “Xiao wanyi," Xiandai ertong 5(5) (1942), 9.

${ }^{40}$ Lin Lübin, Ertong shougong (Shanghai, I933), vol. III, I67-68; Lei Jiaxian, Guoshi wanju zhizuo fa (Shanghai, I937), $5 \mathrm{I}$.

${ }^{4 \mathrm{I}}$ Lisa L. Ossian, The Forgotten Generation: American Children and World War II (Columbia, MO, 20II), 56.

${ }^{42}$ Liu Huanming, "Shei he wo wan," Xiao pengyou 553 (I933), 4I; Boyou and Xiyi, "Ertong nian de nuli," Xiao pengyou 666 (I935), I2; Sun Jie and Ming Min, "Shidai xiao xianfeng," Kangzhan ertong 2(I/2) (I940), n.p. 
combat: Youthfulness may have shielded them from the battlefield but not from becoming acquainted with war. The Chinese may have been inherently peaceable, as textbooks argued, but the nation had to be protected. ${ }^{43}$

Children's periodicals, primary school handicraft textbooks, and materials for educators all addressed the issue of "defense training" or "war of resistance education," offering a playful introduction to arms. Some advocates of defense training did concede that weapons were used to kill but argued that reproducing them was crucial in helping children acquire the military knowledge needed to resist the foreign invasion. Detailed explanations were therefore provided on how to construct a wide array of military apparatus - from aircraft carriers and gas masks to machineguns and anti-aircraft artillery - out of scrap or other easily obtainable materials; these toys were sometimes referred to as "defense models" or even "teaching material." ${ }_{4}$ Throughout unoccupied China, schoolchildren engaged in these modeling activities and had their achievements duly appraised and ranked. ${ }^{45}$ Reproduction was also understood as the springboard to future invention: Toy- or model-making initiated children into labor, resourcefulness, technology, and warfare simultaneously.

In China, as in other theaters of war, basic knowledge of aviation was considered necessary to resist aggression. Thus, for example, kindergarten teachers in rural areas fashioned airplanes out of cigarette packets to introduce their young students to aviation. According to children's magazines, constructing toy airplanes would help train the young to defend China against its imperialist enemies. ${ }^{46}$ However, a survey conducted in the mid I930s found that few children in the countryside liked toy planes, to the disappointment of some commentators. Interest in "national defense education" toys like airplanes was imperative, they argued:

43 Peter Zarrow, Educating China: Knowledge, Society, and Textbooks in a Modernizing World, I902-I 937 (Cambridge, 201 5), 68, I 27.

44 Lianghuan, "Guofang moxing zhizuo fa"; Zong Lianghuan, Junxie moxing zhizuo fa (Shanghai, I933); Xu Jian'an and Yao Jiadong, eds., Guofang xunlian xiaoxue gongyi jiaocai (Shanghai, I936); Wu Ding, "Kangzhan shiqi xiaoxue kecheng ji jiaocai zhi yanjiu," Jiaoyu zazhi 28(5) (1938), 43; Rui Xuanzhi, "Xiaoxue kangzhan jiaocai yi shu," Jiaoyu zazhi 28(6) (I938), 33; Jiang Xiangnan, “Kangzhan wanju,” Xiandai ertong 6(4) (1942), I36-38. On the mobilization of orphans in wartime, see M. Colette Plum, "Lost Childhoods in a New China: Child-Citizen-Workers at War, I937-I945," European Journal of East Asian Studies I I (201 2), 237-58.

45 "Quanguo xiaoxue chuzhong xuesheng zizhi feiji gaoshepao moxing chengji pingpan biao," Guangxi sheng zhengfu gongbao I I 38 (I94I), 7-I I.

${ }^{46}$ Sun Mingxun, Laogong you'er tuan (Shanghai, I935), I53; Shenzi, "Feiji," Xiao pengyou 754 (I937), 23-25; Jiang Xiangnan, "Kangzhan wanju," Xiandai ertong 6(3) (1942), 100-02. 
The absence of such interest could only be the result of unfamiliarity and could thus be easily remedied by encouraging aeromodeling in handicraft classes. ${ }^{47}$ One suspects that children might sometimes have seen - and despised - making "defense toys" as homework, on account of their connection to school- and state-promoted activities.

Nonetheless, some youngsters did echo the association between toys and defense. One boy voiced regret that he was too small to kill the enemies with his airgun, for example. Some used improvised corncob "bombs" to play at bombing the Japanese. ${ }^{4}$ Other boys, however, simply played war games out in the street or made their own toy pistols, waterguns, and broadswords, displaying perhaps a martial spirit but not necessarily militant defense-mindedness. ${ }^{49}$ Military toys, toy-making, and play did not inevitably entail a conscious acceptance of the full anti-imperialist mobilization package, and of course toy-making was, to many, simply a necessity. Raising their "national consciousness" might, indeed, not have been the main reason why children engaged in play.

\section{LEISURE FOR THE “SUCCESSORS TO THE REVOLUTION"}

Internal military conflict might have come to an end in China by late I949, but mobilization did not. Although the Communists claimed to be radically different from the Nationalists, their early I950s discourse of childhood and play was rather similar to that of their predecessors, albeit with more emphasis on the collective and more extensive politicization and regimentation. Texts for educators and children's magazines disseminated the message that the young, as "successors" to a valiant cause, had to cultivate themselves to be "new" and "useful" people who would be able to construct and protect the motherland. Even more markedly than before, mere amusement was despised in favor of purposeful leisure: A "befuddled life" ${ }^{\circ}$ was no longer tolerable. ${ }^{5 \text { I }}$ If grown-ups were

47 Luo Zixin and Wang Zhilu, "Xiaoxue ertong xingqu de diaocha yanjiu," Jiaoyu zazhi 26(8) (1936), 76.

${ }^{48}$ Yang Yijing, "Qiqiang," Xiao pengyou 555 (1933), 38 ; Henrietta Harrison, The Man Awakened from Dreams: One Man's Life in a North China Village, I857-1942 (Stanford, 2005), I62.

49 Zhu Caipei, "Xinnian de youxi," Xiao pengyou 444 (I93 I), 69; Wang Meng, Wang Meng zizhuan. Diyibu, bansheng duoshi (Canton, 2006), 45; Fu Zhengyi, Jianji rensheng: Fu Zhengyi zizhuan (Beijing, 2007), 6.

$5^{\circ}$ Fang Jianming, "Qingzhu liu yi ertong jie," Xin ertong shijie 45 (I950), 6.

${ }^{51}$ Fang Yuyan, "Liangge shijie de ertong shenghuo," Renmin jiaoyu 2 (I950), 27-30; Zhang Guofan, "Yinggai lizhi zuo ge xin ertong," Xin ertong 28 (I950), 2; Che Xiangchen, 
infantilized and the young made adult in the People's Republic, as JeanPierre Diény rightly argued, ${ }^{52}$ this was only an intensification of Republican attitudes.

Like their precursors, the Communists looked upon play as an educational tool. Play was supposed to teach children love of labor, collectivism, tenacity, discipline, and politeness. ${ }^{53}$ And mobilization. Parents and educators were repeatedly advised to guide and supervise play, albeit without stifling children's creativity. Creativity was to be rechanneled, however, if it went in the wrong direction. Around 1950, for example, some primary school children in Beijing who had wanted to be the Americans in a play battle because they considered them to be more vigorous than their opponents were set straight by means of thorough "current affairs education" about the Korean War. Military games with toy weapons were fine for cultivating courage, vigilance, and hatred of imperialism, but only when carried out according to the script. ${ }^{54}$ Posing as a People's Liberation Army (PLA) soldier or as a volunteer fighter against "American devils" in Korea was laudable, but impersonating "evil characters" could allegedly result in children taking on their bad ways. Bad characters could, however, be impersonated on occasion for reasons of expedience. For example, one player in "Cooperation Between the Army and the People," a game recommended for primary schools in 1949, was to take on the role of Chiang Kai-shek. ${ }^{55}$

Whether defined as children's "closest friends" or "tools to educate children," playthings remained catalysts of mobilization under the Communists, but increasingly in conjunction with "meaningful" group activities such as toy-making and collective play. Children were in fact soon expected to make toys rather than simply play with them like toddlers. Experts claimed that, in contrast to the previous regime's

\footnotetext{
"Haohao xuexi, jianshe zuguo," Hao haizi 8I (I953), I; "Xingfu de xia yidai," Renmin huabao 6 (I954), 4-7; Zhongguo fulihui shaonian gong, "Shanghai shaonian gong gongzuo jingyan," Renmin jiaoyu 6 (1956), 48-5I.

52 Jean-Pierre Diény, Le monde est à vous. La Chine et les livres pour enfants (Paris, I97I), 7 .

53 Zhong Zhaohua, “Zenyang jiao xiao haizi youxi,” Xin ertong jiaoyu 7(5) (I95 I), I6-I7; Ya Su, "Xuexi Sulian dui you'er jiaoyu de fangfa," Xin Zhongguo funü 6 (I953), I 2.

${ }^{54}$ Chen Dingxiu, "Jieshao “ertong leyuan," Xin jiaoyu 2(6) (I95I), 37; “Jieshao Beijing shi shaonian ertong dui de shishi jiaoyu huodong," Renmin Ribao (I95I), in Jiaoyu ziliao congkan she, ed., Xiao xuexiao de shaonian ertong dui (Shanghai, I95 I), 80-83.

55 Zhong Zhaohua, "Zenyang jiao xiao haizi youxi," I6; Lüda shi minzhu funü lianhehui fuli bu, ed., Zenyang jiaoyu haizi (Dalian, I953), 37; Kou Xiulan, "Youxi," Xin Zhongguo funü I (I955), 2I; Xiao xuesheng chang you ji (Shexian, Henan, I949), 37.
} 
negligence, the government was now ensuring that all children had "new" and "appropriate" toys. Again, a good plaything should instruct, and foster a love of labor or an interest in science. Although some educators argued that dolls ought to look Chinese, the struggle against foreign toys subsided, most likely because the few available items hailed from socialist countries. $^{56}$

Toy-related mobilization in the early I950s could involve volunteerism, as when primary school children (were) rushed to create playthings for hastily established kindergartens. Or it could involve manualintellectual mobilization, as when home- or school-made toy replicas of machines - defined as "models" - were held up as examples of children's engagement with science and technology, and of their eagerness to learn the productive skills needed to rebuild and protect China. ${ }^{57}$ And, despite the fact that the martial spirit was no longer mentioned, toys could be instruments of martial mobilization for political and quasi-military struggle. In all its facets, the discourse of activism tended to address "children" - yet it was still a masculine-coded model that girls had to pursue.

\section{TOYS AS AGITATION TOOLS: BETWEEN TANKS AND DOVES}

Chinese children had to learn to be concerned with political affairs; they should be "always prepared." ${ }^{8}$ In the early 1950s, the Taiwan question and the Korean War offered opportunities for them to (im)prove their preparation. Mobilization was promoted mainly through toy- or modelmaking, in a happy blend of creative labor, frugal resourcefulness, and political education. In such activities, youngsters were expected to display a remarkable fervor that reflected the intense gratitude they presumably felt for enjoying such happy lives. As in the Republican era, the mobilization of children involved ridiculing enemies and training to defeat them as well as the acquisition of basic scientific-technological skills.

${ }^{56}$ Fu Baochen, ed., Ertong wanju zhanlan jiniance (Chengdu, I950); Beijing shi gongshang guanli ju, "Benju guanyu zhaokai ertong wanju zuotanhui de hanjian zuotanhui jilu ji juxing ertong wanju zhanlanhui wenti xiang shifu de baogao ji qi youguan cailiao," Beijing Municipal Archives, file 22-12-896, I950-1952; Zhou Shufen, "Zenyang wei haizi xuanze wanju," Xin Zhongguo funü I (I954), 3 I.

57 Yang Guang, "Meili de wanju," Xiao pengyou I045 (1952), I2-I3; Xinhua she, "Zhou zongli he re'ai kexue de xiao pengyou zai yiqi," Xin shaonian bao 408 (I955), I.

${ }^{58}$ Feng Wenbin, "Shike zhunbei zhe," in Zhongguo xin minzhuzhuyi qingnian tuan Xinjiang sheng gongzuo weiyuanhui, ed., Zhongguo shaonian ertong dui shouce (Dihua, 1952), 7-8. 
Children were expected to show support for the PLA's efforts to "liberate" Taiwan. They also had to be prepared to act, as did some primary school pupils who reportedly trained to help the army by devising makeshift parachutes with cloth doll dummies. ${ }^{59}$ Youngsters were also supposed to develop a sound political awareness, in school and at home. Methods for cultivating it included the use of recreational "teaching aids" that primary school children could craft with their teachers. One such teaching aid, named "Blast the War Criminal," involved constructing figurines of "war criminals" such as Chiang Kai-shek and Dwight Eisenhower and then lighting firecrackers placed on their heads. ${ }^{60}$ Toymaking manuals suggested that, to entertain themselves, children draw "the common enemy of the Chinese people, wretched Chiang" with the body of a dog, as he was "the running dog of American imperialism," and then shoot him with bamboo arrows tipped with suction cups. ${ }^{6 r}$

Patriotic education also involved participation in the campaign "Resist America, Aid Korea." Primary school students could apparently acquire a solid yet enjoyable anti-imperialist extracurricular education by fashioning "highly interesting" games as "War Criminal Enters the Coffin": Players threw balls at a figurine to try to topple it and make the "coffin" lid close over it. ${ }^{62}$ Or children could craft toy planes - as a poem in the periodical Good Children suggested - to go first to bomb the American imperialists and then fly on to Beijing to see Mao Zedong. ${ }^{63}$ Toy-making could also involve a fruitful combination of political and scientific competence. Optical illusions, manuals advised, could be investigated by making a thaumatrope that showed a dagger - the people's "peaceprotecting armed forces" - piercing a "US-armed Japanese warlord" and the maneuvering hand of "an American warmonger" behind him. To comprehend the principle of gravity, children could produce the revamped, or rearmed, rendition of a tumbler toy in the shape of a fearless soldier, ever standing to safeguard the people, the motherland, and peace. ${ }^{64}$

59 Guo Lin, "Women shi zheyang peiyang ertong de chuangzaoxing de," Renmin jiaoyu 2 (I950), 52.

60 Xu Linshou, Xiaoxue jiaoju zhizuo (Shanghai, I953), I69.

${ }^{6 r}$ Xiong Dafu and Fu Tianqi, Ziji zuo wanju (Shanghai, I953), 84-86. "Wretched Chiang," which could also be rendered as "damned Chiang," is the translation of "Jiang gaisi," a pun on Chiang Kai-shek's name as pronounced in Mandarin, Jiang Jieshi.

${ }^{62} \mathrm{Xu}$ Linshou, Xiaoxue jiaoju zhizuo, I70.

${ }^{63}$ Yin Zhenwu, Liu Ruiying, and Wang Minggang, "Zhizao xiao feiji," Hao haizi 7I (I953), 2 I.

${ }^{64}$ Xiong Dafu and Fu Tianqi, Ziji zuo wanju, introduction, 8-9, 5I-52. 
Hardly any mention of these activities can be found in contemporary accounts, although some children seem to have echoed the discourse of mobilization. Primary school boys purportedly made toy rifles for toddlers so that they could learn to protect the country as the Chinese Volunteer Army did. Student groups who engaged in learning about science and technology by crafting models out of scraps proudly reported that had their "Liberation tank" artillery been real, it would have "killed quite a few American devils." ${ }^{5}$ Chinese boys played games such as "Resist America, Aid Korea." Even foreign boys living in China pretended that their siblings were spies for Chiang Kai-shek and, together with their Chinese playmates, attacked them with mudball "hand grenades." As before, children crafted toy weapons and played war without explicitly attaching militant significance to it. ${ }^{66}$ That is, they apparently were not fighting for peace in their play.

Antithetical as this may seem, icons of both war and peace coexisted in prescribed leisure. Toy-making suggestions for children encompassed cardboard doves, and the periodical Women of New China alerted mothers to the ideological correctness of peace dove puzzles. ${ }^{67}$ Revolving-horse lanterns, which youngsters were encouraged to construct in order to learn about the effect of heat on air, could be decorated with peace doves or images of the Chinese Volunteer Army pursuing American soldiers. ${ }^{68}$ Education should apparently promote patriotism and internationalism. Like the Soviet Union, the "new China" and its children were striving for peace. ${ }^{69}$ Very seldom did

${ }^{65}$ Liu Guanying, "You yiyi de liwu," Xin shaonian bao 253 (I952), 3; Lin Fuqi, "Wode 'jiefang hao' tanke," Kaiming shaonian 72 (I95I), 44-45.

${ }^{66}$ Ralph Lapwood and Nancy Lapwood, Through the Chinese Revolution (London, I954), 82; Zhou Zhangshi, "Women nage shihou de wanju," Yuwen jiaoxue yu yanjiu 7 (1997), 20; Ye Weili with Ma Xiaodong, Growing Up in the People's Republic: Conversations Between Two Daughters of China's Revolution (New York, 2005), 34; Cui Puquan, "Wo xiao shihou de ertong wanju," in Bian Jian, ed., Chayu fanhou hua Beijing (Beijing, 2006), I73-74.

${ }^{67}$ Zhou Shufen, "Zenyang wei haizi xuanze wanju," 3 I; Wen Quan, "Heping ge," Hao haizi 66 (I953), 28. On the peace dove icon, see James Z. Gao, "War Culture, Nationalism, and Political Campaigns, 1950-1953," in C. X. George Wei and Xiaoyuan Liu, eds., Chinese Nationalism in Perspective: Historical and Recent Cases (Westport, 200I), I80; on doves, and children as icons, see Chang-tai Hung, Mao's New World: Political Culture in the Early People's Republic (Ithaca, 20I I), I9I-98.

${ }^{68}$ Guo Yishi, "Zoumadeng," Zhonggguo shaonian ertong 30 (I950), I3; Jinzhou shi Taihe wanquan xiaoxue, "Jiechuan kongqi de mimi," in Zhongguo xin minzhuzhuyi qingnian tuan zhongyang shaonian ertong bu, ed., Shaonian ertong dui de huodong (Beijing, I95I), 55-56.

69 Mu Shaoliang, "Women de jieri," Xin ertong shijie 45 (I950), n.p.; Wang Jingpu and Zhang Zonglin, "Aiguozhuyi jiaoyu zai youzhiyuan,” in Xu Teli, et al., Lun aiguozhuyi 
experts recommend supplying children with toy tanks or guns, and playthings from socialist countries were extolled as nonviolent, as opposed to American "warmongering" toys. Yet Chinese factories churned out toy tanks and guns as well as peace doves, as peace-loving children in stories were "provoked" to react against bullies who boasted about their American toy bayonets. ${ }^{\circ}$ And the military was a constant presence. Beginning in kindergarten, children were taught to love and emulate the army, which was represented as compassionate and protective. ${ }^{7 \mathrm{I}}$ Tanks appeared in pictures that were used to decorate classrooms. Toy-making texts featured sorghum stalk warships. Pedagogues still included artillery pieces among the shapes suggested for assembling blocks. ${ }^{72}$ The conciliatory attitude thus went hand in hand with reminders of the necessity of vigilance, indicative of an undercurrent of insecurity. Children's periodicals, too, reiterated that lurking without and within were enemies - including imperialists, capitalists, and Nationalists - who were eager to destabilize the new China and to jeopardize world peace. Accordingly, permanent mobilization was required. ${ }^{73}$

Leaving aside the point that doves (and even the army) can signify militancy for peace, some of the assessments of playthings displayed at a 1950 exhibition may help explain the seemingly incongruous coexistence of doves and armaments because they illuminate how the difference between war and resistance was constructed and perceived. Planes and tanks laudably fostered an interest in science, according to one observer, but they had the downside of "arous[ing] the idea of warfare" in the young. At the same time, a figurine of a Japanese soldier was commended for "arous[ing] the idea of resistance war." 74 Warfare was judged to be bad, but wars of resistance were good even if they, too, entailed combat

jiaoyu (Beijing, I95I), I06-I4; Peter N. Stearns, Childhood in World History, and edn. (London, 20II), I07.

70 "Zhongguo renmin duiwai wenhua youhao xiehui Shanghai shi fenhui guanyu Deyizhi Minzhu Gongheguo ertong wanju zhanlanhui de wenjian," Shanghai Municipal Archives, file C37-2-49, I954-1955; Xi Jian, "Renqing diren," Shaonian ertong I 8 (I950), 7-8.

${ }^{71}$ He Gongchao, "Haoren yao dangbing," Xin ertong shijie 44 (I950), 24-25; Ding Hua, "Beihai you'eryuan san nian lai shi zenyang jiaoyu haizimen de," Renmin jiaoyu 6 (I953), I4.

${ }^{72}$ Xing Shuntian, Jiaoshi buzhi tuhua (Shanghai, I950), fig. I0; Zhonghua quanguo minzhu funü lianhehui ertong fuli bu, ed., Shougong he tuhua (Beijing, I950), 29; Wu Chengqi, "Chuanxin jimu," Xin ertong jiaoyu 8(2) (I952), 28.

${ }^{73}$ Fang Bai, "Xin Zhongguo de youxiu ernü," Zhonghua shaonian 6(22) (1949), 3-4; Tang Yue, "Zenyang qingzhu women de jieri?" Xin ertong shijie 69 (I95I), n.p.

${ }^{74} \mathrm{Fu}$ Baochen, Ertong wanju zhanlan jiniance, 4I, 44. 
and violence. Criticizing war does not necessarily amount to rejecting confrontational mobilization, especially when it is associated with resistance to perceived aggression. Moreover, war and violence can be legitimized and rationalized as just, be it to repel invaders, as was the case in the Republican era, or for the sake of revolution or political goals, as in the Communist era. ${ }^{75}$ The cohabitation of peace doves and antagonistic leisure can thus be situated within the paradigm of resistance versus war: Warmongers and criminals can be joyfully smashed by righteous resisters armed to preserve peace.

\section{CONCLUSION}

Taking children's toys as "a silent signifying dialogue between them and their nation, ${ }^{76}$ this chapter has explored an aspect of the top-down part of that dialogue, the impact of which is difficult to determine because most data on childhood tend to be "adult-generated or adult-controlled." 77 Sketchy impressions gathered from accounts suggest that children appropriated selectively from adults' efforts to mobilize them. Yet, high-handed as it may have been, the rhetoric of activism was acting on, and responding to, assumptions and urgencies (perceived humiliation, nationalism, belief in education and malleability) that made it intelligible to children and adults alike.

Whether in times of war or nominal peace, mobilization through leisure did not necessarily imply outright belligerence. Rather, it encouraged patriotism, discipline, political and technical competence, physical and moral strength, and determination: in other words, the capacity to resist rather than attack. Mobilization was constructed as defensive: It would save the nation from "extinction," repel invaders, or protect peace. Ludic fierceness was legitimated and simultaneously downplayed as just preservation and rightful opposition to real or perceived external encroachment.

75 Sheldon Lu, "Beautiful Violence: War, Peace, Globalization," positions I2(3) (2004), 760, 763; Stephanie Donald, "Children as Political Messengers: Art, Childhood, and Continuity," in Harriet Evans and Stephanie Donald, eds., Picturing Power in the People's Republic of China: Posters of the Cultural Revolution (Lanham, MD, I999), 80.

${ }^{76}$ Walter Benjamin, "The Cultural History of Toys" (1928), in Walter Benjamin: Selected Writings, Volume II, part I, I927-I930, ed. Michael W. Jennings, et al. (Cambridge, MA, I999), II6.

77 Thomas J. Schlereth, "The Material Culture of Childhood: Problems and Potential in Historical Explanation," Material History Bulletin/Bulletin d'histoire de la culture matérielle 2I (I985), II. 
Toys were sometimes called models or teaching aids. This might signify a wish to legitimate playthings by disavowing the play element, perhaps deemed frivolous when connected to grave national concerns. The name change, in other words, might have been meant to alter the perception of the object: You do not use trifles when playing for keeps. Alternatively, the name rectification might have signified a culture of imitation/emulation whereby toys became in fact and in name the props for rehearsing adult responsibilities. Conversely, calling war toys "defense toys" or expunging the martial spirit in name while cultivating it in fact might suggest the wish to downplay antagonism in favor of just resistance. The very concept of the military toy is in fact complex. Toys that are not inherently military (tangrams, revolving-horse lanterns) could be deployed to cultivate quasibelligerent attitudes. Indeed, as Brian Sutton-Smith points out, knowing the context in which a plaything is used is key to identifying its effects. ${ }^{78}$ Calling war toys "educational," as many experts did, was not necessarily an oxymoron: If playthings were tools for instruction, and if the goal of education was to produce useful people, a tool that conveyed military knowledge - knowledge that could be applicable in a time of perceived threat - could thus be educational.

The seemingly contradictory stances of cherishing children while acquainting them with the battlefield can, finally, be explained by referring to their role as national symbols. Ostensibly, the Republican and Communist regimes both set great store by children's wellbeing and accorded them high status. In return, children were asked to perform duties that included reciprocating the protection they received from the state. Trained by "toys," children were supposed to mobilize and struggle to preserve the renewed personhood, and nationhood, that they owed to the state.

${ }^{78}$ Brian Sutton-Smith, Toys as Culture (New York, I986), I I, 25 I. 